\title{
Attending Weak Signals: The Prevention of Work-related Illnesses
}

\section{Roy Liff'}

Associate Professor, University of Gothenburg, Gothenburg Research Institute, School of Business, Economics and Law, Sweden

\section{Ann-Charlotte Eriksson}

Degree of Master of Medical Science, Independent Researcher

\section{Ewa Wikström}

Professor, University of Gothenburg, Department of Business Administration, School of Business, Economics and Law, Sweden

\begin{abstract}
This article examines the characteristics of communication among managers, human resource (HR) experts, and occupational health care specialists, as they deal with such informal information as weak signals in the prevention of work-related illnesses, using a theoretical framework in which the prevention of work-related illness is analogous to theory on crisis management.

This is a qualitative study in which individual and focus-group interviews were conducted in a Swedish context with occupational health care specialists, managers, and HR experts.

The results suggest that organizational solutions have failed and continue to fail at controlling workers' health problems, although the main difficulty is not in identifying the 'right' individually oriented weak signals. Rather, it is upper management's reliance on formal information (e.g., statistics and surveys) - because of the difficulty in supplementing it with informal information (e.g., rumors and gossip) - that makes it difficult to improve traditional health and safety work.
\end{abstract}

\section{KEYWORDS}

Formal information / informal information / occupational health services / qualitative / weak signals

\section{DOI}

To be announced

\section{Introduction}

$\mathrm{n}$ this article, we describe difficulties and opportunities in occupational health and safety (OHS), particularly in occupational health care service $\left(\mathrm{OHCS}^{1}\right)$ intended to prevent work-related illnesses ${ }^{2}$. Such illness-preventive measures, which are often seen as interventions to reduce the occurrence of work-related illnesses, include individual and structural approaches and methods aimed at improving employees' health and wellbeing (Rootman, 2001). Törner and Pousette (2009, p. 401) explain that workplace safety

\footnotetext{
${ }^{1}$ Corresponding author: E-mail: roy.liff@gri.gu.se.
} 
relates to people's competences, values, and attitudes. Preventive measures directed toward the structural-environment causes of work-related illnesses may include unhealthy organizational and social conditions in the workplace, such as people's interactions with their colleagues or managers and with the organizational environment as a whole.

The aim of this study is twofold: a) to explore managers' communications with HR specialists and occupational health experts using weak signals, and b) to examine how specialists and experts respond to these signals and adopt strategies related to illness prevention.

The effectiveness of measures for preventing illnesses has been criticized because evidence-based methods are lacking and because organizational decision makers regard such methods as health examinations as too costly (Ahnmé Ekenryd et al., 2012).

The topic of OHCS may be regarded as part of the OHS research field, especially the field of OHS management (OHSM). According to Gallagher (2000), OHS management system (OHSMS) was designed to manage and control the systematic work of examining and improving work processes that are conducted by work teams specially trained in problem-solving techniques. Such systems involve formalized routines that focus on systematic management, documentation, and control procedures

OHSMS often includes work environment policies, performance measurements, and audit procedures into the mix. Rocha (2010) concludes that organizations frequently use such systematic work to create an environment in which illness prevention and wellbeing are prioritized but states that researchers disagree on whether such systems achieve this aim. Kamp and Le Blansch (2000) argue, for instance, that health-management systems lead to bureaucratization and distract organizations from the creativity and experimentation necessary for learning how to avoid accidents. For an extensive overview of the criticism of OHSMS, see Rocha (2010).

Hohnen and Hasle (2011) argue that certified systems emphasize facts that can be measured and audited, and they de-emphasize 'the professional judgement of workers' (p. 1029). They also argue that even if the systems were to identify and control all potential risks, this requirement means, in principle, that certified systems control mainly accidental risks. They suggest, therefore, that organizations with 'more complex, multifaceted usually psychosocial work environment issues' (p. 1029) - require approaches that differ from the traditional safety management system approach.

It could be claimed that the problems with standardized procedures and systems stem from implementation failures that could be remedied gradually by more and more systemized safety work. The systems approach rests on the assumption that risks can be anticipated, an assumption that can lead to rigid responses when unanticipated and unavoidable problems occur (Pidgeon, 1998). This insight leads to the conclusion that the systems approach to safety management needs to be supplemented.

Although one approach to analyzing OHS emphasizes the role of systems and the ways in which management's actions may be shaped by the systems, another approach emphasizes the role of management in shaping not only systems but also the way safety matters are communicated in an organization. When managers emphasize safety with their workers, they are signaling that this is an issue of value to everyone in the organization (Hofmann \& Stetzer, 1998). Furthermore, when managers demonstrate trust in their workers, workers are more inclined to reciprocate by supporting organizational safety goals and by acting responsibly in ways that help prevent accidents and promote safety (Törner \& Pousette, 2009).

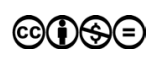


Previous research stresses the importance of strong leadership for the promotion of collective values, norms, and attitudes in an organization that encourages habits and attitudes related to workplace safety. Most research has focused on occupational safety and managers' identification of information or signals based on formal (traditionally measurable and auditable) facts. In a summary of this issue, Törner and Pousette $(2009$, p. 407) state: 'The mechanism [how safety performance is influenced] appears to be dependent on successful development of open and mutually trustful vertical as well as horizontal relationships'. In several studies (Andriessen, 1978; Hofmann \& Stetzer, 1998; Törner \& Pousette, 2009) that have investigated variables influencing safety performance, however, little attention has been paid to the detailed content of managers' communication with workers or experts - communications that could catch problems their early stages. However, it may be questioned whether these experts have the knowledge to make professional judgments about weak signals and are the right partners when making judgments on weak signals, since OHCS specialists in previous research have been criticized for not having the right competence on organizational preventive measures (Ahnmé Ekenryd et al., 2012; SOU, 2004: 113). Furthermore, OHS organizations that offer product like services without dialogue with their customers and without aligning their services to the customers perceived needs have been strongly criticized (SOU, 2004: 113, p. 115). This criticism has been ongoing and especially concerned the inability to work with prevention of work-related illnesses and health promotion (SOU, 2011: 63, p. 44).

We had two research questions. a) How do hospital managers, OHCS specialists, and HR experts discover, interpret, and attend to weak signals that may indicate potentially severe work-related illnesses in their early stages? b) What are the responses to such weak signals after they have been discovered and interpreted? HR specialists are included in this study because they often serve as a link between OHCS specialists and the managers in the organization to which the managers and HR specialists belong.

We researched these questions in several public-sector settings in Sweden - mainly in hospitals of varying sizes, in which a group of managers and other professionals have responsibility for the workplace health and wellbeing of workers. We examined the relevance of information in the development and use of measures of illness prevention. By studying managers, workers, specialists, and experts in their day-to-day work, using interviews and observations of actor-to-actor episodes, we contribute to knowledge on the use of information in the area of OHS.

A starting point for our article is the idea that the difficulties with preventive, workrelated illness measures are the same as the difficulties generally encountered in trying to prevent other crises. According to Weick and Sutcliffe (2006, 2007), an organization's ability to handle unexpected situations and prevent crises depends on the ability of its leaders to be highly observant in noting weak signals and abnormal details and in acting on them promptly. Close observation requires, among other things, that leaders see when expectations are not met or planned activities are not performed. Weick and Sutcliffe base these conclusions on studies of high reliability in organizational systems such as air traffic control systems, power generation systems, and aircraft carrier management systems. These systems cannot be tested by trial and error, using planning tools or strategies that allow employees to learn from the consequences of the tests. For some organizations, trial and error can be catastrophic if the trial does result in errors (Weick, 1987).

Weick and Sutcliffe (2007) explain that high-reliability organizations like hospital emergency departments and nuclear power plants must have much greater awareness 
of the importance of weak signals, abnormal details, and rumors than other organizations do. They add that this is a matter of 'uncover[ing] early signs that expectations are inadequate' (p. 23). They describe early weak signals as small events and clues about unplanned situations or issues such as unintended consequences, which, if observed at an early stage, are generally easier to manage. Because weak signals may simply take the form of intuition that something is not right, it is essential to resist the temptation to treat them as unimportant and thereby fail to evaluate them (Weick \& Sutcliffe, 2007).

Following this introduction, we present previous studies and a theoretical framework. In the third and fourth sections, we first describe the setting of the study and next how we collected and analyzed our empirical materials. In the fifth section, we present our analysis. In the sixth section, we discuss our findings. The final section contains our concluding remarks.

\section{Weak signals and sense-making}

Ansoff (1975, p. 23) writes that weak signals appear 'early in the life of threat, when the information is vague and its future course unclear'. Weak signals, which may appear in both informal and formal channels, may be incomplete, unstructured, and fragmented (Rossel, 2011). In fact, weak signals may even be ignored, despite their relevance to the situation (Holopainen \& Toivonen, 2011; Rossel, 2011), because they can be difficult to distinguish from irrelevant signals (Cunha \& Chia, 2007). Because weak signals are usually vague in their relationship to an event or behavior, organizational leaders are more inclined to focus on other key business issues and problems and ignore the more peripheral issues. This is likely to happen even when the weak signals pose threats or offer opportunities (Cunha \& Chia, 2007).

The usefulness of weak signals in detecting unexpected events, like, work-related illnesses, derives from the realization that they can be warning signs of accidents or other crises, identified only retrospectively. According to Turner (1978), a crisis often results when warning information about an impending crisis, which is often available many years before the crisis, was ignored or misinterpreted because of its early timing. Weick's (1988) concept of retrospective sense-making, in which people give order and meaning to events, and Roux-Dufort's (2009, p. 5) description of a crisis as a 'process of gradual accumulation of weaknesses' point to the idea that weak signals, if attended to, may be the warning signals that help avoid accidents and traumas.

Roux-Dufort (2009) proposes a procedural theory of crisis, by which a crisis builds up in four stages. An abnormal event occurs in Stage 1, but the event is assumed to be normal or almost normal because it is nearly invisible and not yet disruptive of everyday operations. The abnormality increases in Stage 2. A triggering event then occurs in Stage 3, revealing the abnormality and the associated vulnerability of the organization. At this point, management has lost control over interruptions in operations. A complete destabilization of the organizational environment occurs in Stage 4. Now the crisis is a known fact, and the fear is that it will only escalate in severity.

Roux-Dufort (2009, p. 5) describes Stage 2 abnormalities as 'Individual conflicts, persistent rumours, downtime, newspaper articles, shares under pressure ...' At this stage, organizational vulnerabilities begin to accumulate because leaders have not responded to these weak crisis signals, and a breeding ground for a crisis has been created. In the 
incubation phases (Pidgeon \& O’Leary, 2000; Turner, 1976), ignored vulnerabilities are predictors of unexpected disruptions. Reason (1990) uses the term 'the fundamental surprise' to describe this difference in the perception between the world and reality.

With this understanding of a crisis as a process that moves through stages, it makes sense to think about leaders' abilities to identify the beginning of a crisis, despite the difficulty of doing so (Roux-Dufort, 2009). According to Roux-Dufort, leaders tend to ignore the potential complexity of future situations, thereby ignoring the consequences of the cumulative effects of abnormalities and vulnerabilities and finding themselves in uncontrollable situations. Leaders' abilities to prevent crises depend on their collective abilities to interpret the weak signals that appear in Stage 2. They need to investigate the internal causes of these signals and create preparedness action plans for dealing with unexpected and exceptional events, should they occur.

Leaders may not respond to weak signals because of their tendency to filter these stages, and may therefore fail to take the necessary preventive action (Ansoff, 1975; Rossel, 2011). According to Rossel, there are three kinds of filters. The first, the surveillance filter, defines the field of observation, and may work well in blocking irrelevant signals; it may also block relevant signals, however, rendering them undetected.

People who pay close attention may be trapped in the second filter, the mental filter, which means that they cannot interpret signals. This is easily the case if the signal does not fit into their frames of reference and the prevailing organizational cultures. Weak signals are often ignored if they are unusual and run contrary to general expectations about the future and about traditional ways of looking at things. When we observe something outside our experience and frame of reference (e.g., our opinions and biases), our interpretation is influenced. According to Rossel, such opinions and biases stem from taken-for-granted knowledge, normative thinking, and personal aspirations and attitudes. At this point, the third filter, the power filter, may block the weak signal because a threat to the organization is perceived.

Day and Schoemaker (2004) argue that the difficulty lies in detecting relevant weak signals and dealing with these signals without becoming too distracted from the tasks at hand. Haeckel (2004) argues that the adaptive organization, operating in an unpredictable environment, must make a great effort to explore these peripheral, weak signals. Adaptive organizations must institutionalize a core competency for identifying and distinguishing these weak signals from extraneous signals that are merely noise.

The highly relevant ability of OHCS to contribute to work-related illness prevention depends on another ability: the ability to discover informal information transmitted by the weak signals that workers and managers send. Such signals may indicate potential problem areas in the organizations (e.g., hospitals) as a whole that can lead to illnesses. According to Cunha and Chia (2007), the main problem with weak signals is not the difficulty in detecting them, but the difficulty in separating relevant and irrelevant weak signals. An organization must therefore have the necessary conditions to distinguish relevant weak signals from irrelevant noise in order to acquire a full understanding of potential crisis situations.

\section{Sense-making}

It may be assumed that formal data from personnel files and surveys, including workers' surveys, contribute to decisions on organizational and leadership issues. It may also be 
assumed that even formal information can be confusing (Hedberg \& Jönsson, 1978), but that confusion may be reduced if informal information, like oral communications, rumors, and observations, are also used in decision-making (Hall, 2010; Jönsson, 1998). Although leaders may use informal information to interpret formal information (Preston, 1986), they may also use formal information to suppress informal information, so that relevant, early signs of a need for change are neglected (Hedberg \& Jönsson, 1978). This finding suggests that leaders should discuss and analyze early weak signals that have not yet influenced the formal information, to understand fully what the formal information is conveying about activities and events in the organization. Thus, informal information can help people better interpret formal information (Hopwood, 2009).

According to Weick (1987), direct, face-to-face communication is the best way to obtain rich information that may contain weak signals; that such communication transmits information visually by facial expressions and body language. Team collaborations and networks in which members with different backgrounds and skills can focus on different things and offer different interpretations are also beneficial in the identification of weak signals (Weick, 1987). Before leaders make decisions based on weak signals, however, they need to examine these signals carefully because a decision is not always required.

Weick and Sutcliffe (2007) have noted that managing the unexpected often means having to make a strong response to a weak signal. Leaders who act in this way are typically more mindful of unintended consequences. They recognize that awareness involves interpretations of weak signals, and this mindfulness may lead to a preventive action. A large repertoire of abilities is necessary if the 'mindful organization' is to be aware of the many possible weak signals (Weick et al., 1999, 2005). Weick and Sutcliffe (2007) claim that mindful organizations have several attributes:

a) an ability to detect small problems, each of which shows that weak signals are building up;

b) a reluctance to simplify weak signals so that it superficially appears as if there were similarities between the previously known situation and the current situation; and

c) a sensitivity to events, demonstrated by paying attention to specialists and front-line players rather than just to managers somewhat removed from events and requirements.

Point b), a reluctance to simplify weak signals, bears a strong relationship to the issue of detecting the 'right' weak signals: which signals should be ignored and which should be addressed.

Weick et al. $(1999,2005)$ provide several examples of organizations that have the required potential to set conditions that match the variation existing in their work environments. This may mean using information that contradicts the information typically used in management decisions; introducing various, divergent perspectives; hiring staff with experience that differs from that already in the organization; and taking a skeptical approach to a story or report from the organization - preparing a different story or report, and generating two observations from one.

Because of skepticism, the organization's members cannot ignore and overlook data, and the relatively weak signals are interpreted, based on different experiences, analytical perspectives, and models. According to Weick (1987), sense-making is probably best achieved in a collective process. When several group members detect weak signals, the weak signals are inevitably discussed. It is noteworthy that formal information may

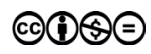


also contain weak signals. A jump in a graphical curve of sick leave at a hospital may indicate that something is going on in that hospital; perhaps a new style of leadership has compromised occupational health.

\section{Methods}

\section{Design, participants, and data collection}

The aim of this study is to explore managers' communications with HR specialists and with experts on occupational health care issues using weak signals, and to analyze how these actors respond to these signals and adopt certain strategies related to illness prevention. Data for the study were collected on many aspects of OHS work, such as worker rehabilitation and the promotion of worker health. The purpose of this explorative study design was to investigate a new field in which little research has previously been conducted and in which few definitive assumptions exist - a design that Patton (2001) recommends for such situations. We also took an interactive research approach with our use of focus-group interviews.

We conducted semi-structured, face-to-face interviews with first-line, operational managers in hospitals; OHCS specialists; and HR experts. In the first round of the selection process, we invited managers and HR experts from all organizations belonging to the same larger organization as OHCS, where these organizations are acting as customers of OHCS.

We aimed for variety in size and service type among the hospitals that volunteered for participation in the research. (See Table 1.) All 24 invitees agreed to participate in the research, and all individuals were interviewed on only one occasion.

We structured our interviews following Kvale's (1996) recommendations on semistructured interviewing, beginning with broad questions and followed by thematic questions:

\section{Initial questions:}

How would you describe the cooperation among first-line managers, OHCS specialists, and HR experts?

What are the organizational places or venues where cooperation takes place? How have they evolved?

What are people's roles and responsibilities? How would you describe their authority? What does the work of illness prevention and health promotion mean? Identify supportive conditions and challenges.

\section{Thematic questions:}

What are examples of prevention (episodes)?

Did something special trigger the episodes?

How did the various actors respond?

What was achieved?

Have illness-prevention measures changed, and if so, how?

How would you describe vertical communication (related to tasks, contacts, venues) with upper level management? 
Table I The interviews

\begin{tabular}{|c|c|}
\hline $\begin{array}{l}\text { Total number of interviews: } \\
24 \text { interviews }\end{array}$ & $\begin{array}{l}\text { Number and roles of interviewees: } \\
7 \text { interviews with first-line managers } \\
12 \text { interviews with OHCS specialists } \\
5 \text { interviews with HR experts }\end{array}$ \\
\hline $\begin{array}{l}12 \text { interviews at the } \\
\text { Regional Occupational Health Services }\end{array}$ & $\begin{array}{l}5 \text { interviews with nurses } \\
3 \text { interviews with psychologists/organizational consultants } \\
\text { I interview with the company physician } \\
\text { I interview with a health educator } \\
\text { I interview with an ergonomist } \\
\text { I interview with the physiotherapist }\end{array}$ \\
\hline 3 interviews at a small hospital & $\begin{array}{l}2 \text { interviews with first-line managers } \\
\text { I interview with an } \mathrm{HR} \text { expert }\end{array}$ \\
\hline 2 interviews at a medium-sized hospital & $\begin{array}{l}\text { I interview with a first-line manager } \\
\text { I interview with an HR expert }\end{array}$ \\
\hline 3 interviews at a large hospital & $\begin{array}{l}\text { I interview with a first-line manager } \\
2 \text { interviews with an HR expert }\end{array}$ \\
\hline 4 interviews at a small hospital & $\begin{array}{l}3 \text { interviews with first-line managers } \\
\text { I interview with an HR expert }\end{array}$ \\
\hline
\end{tabular}

The interviewees provided examples that described real episodes when weak signals were discovered, rather than their 'theories about the world' (Alvesson, 2003). The interviews, which usually lasted about 50 to 60 minutes, were audiotaped and later transcribed. Table 1 summarizes the number of interviews and the roles of interviewees.

We then conducted three focus-group interviews with some of the interviewees (first-line managers and OHCS specialists). The relatively extensive interviewing of HR experts guided us to find examples in which first-line managers had experienced weak signals being discussed. Two first-line managers and one OHCS specialist participated in one focus group, two first-line managers, one OHCS specialist, and one HR expert in a second, and five members of the OHCS management team in a third. We presented results from the respondents' previous individual interviews, including descriptions of episodes. The focus group style of interviewing allowed participants to jog one another's memories as they recalled episodes. These focus groups lasted about 2 hours and were audiotaped and transcribed.

\section{Data analysis}

We analyzed our data in three steps. In the first step, we began by reading our interview and focus-group transcriptions, looking for the most significant episodes. Because a two-person team conducted the research, we were able to engage in interpretative 
discussions on these episodes. We then reread our data, searching for empirical categories and themes in the episodes, with particular reference to cooperation among the actors. We then categorized the actors' statements, looking for patterns and connections in the descriptive content (Kvale, 1996; Strauss \& Corbin, 1990). We initially labeled our first-order empirical categories as 'receiving/catching informal information', 'talking with other collaboration partners about the informal information', and 'understanding and acting upon the informal information'. The respondents' criteria, as revealed in the interviews, were used to judge whether the content in the described examples concerned a weak signal.

In the second step, we used the categories derived from the theoretical framework as precepts for direct content analysis (Hsieh \& Shannon, 2005). We used the following coding scheme:

- Sources of weak signals: Subcodes from the perspectives of first-line managers and OHCS specialists were used to identify weak signals and the methods for their discovery.

- Attending to weak signals as a process: Subcodes from the perspectives of first-line managers and OHCS specialists were used to describe weak signals and preventive work as a process.

Sense-making and initiating an action from weak signals: Subcodes from the perspectives of first-line managers and OHCS specialists were used to record decisions on preventive measures, decision-making weaknesses, and interactions between formal and informal information communication systems.

In the third step, we used iterative analysis to collect interviewee/participant comments in the data we had categorized and coded (Charmaz, 2006; Denzin \& Lincoln, 2011). Table 2 summarizes the results of our data analysis.

Table 2 Theoretical categories and examples

\begin{tabular}{|c|c|}
\hline Theoretical categories & Examples \\
\hline Sources of weak signals & $\begin{array}{l}\text { Ex I:'I hear how they talk about their lives. I'm nearby. I hear } \\
\text { the stress in their voices as well. I am aware the whole time' }\end{array}$ \\
\hline Attending to weak signals as a process & $\begin{array}{l}\text { Ex 2: 'We do not have an agreement about observations. } \\
\text { Yet this is what we do. ... They say: "This is what we need to } \\
\text { work on". Without that, it's just something that we see as a } \\
\text { mission but have not really agreed that we should do it.' }\end{array}$ \\
\hline $\begin{array}{l}\text { Sense-making and initiating an action from } \\
\text { weak signals }\end{array}$ & $\begin{array}{l}\text { Ex 3: The managers in the clinics and departments pick } \\
\text { up weak signals from problems. That works well. We have } \\
\text { discussed the situation when we have three or four cases } \\
\text { from a department. We...then analyse the situation and try } \\
\text { to restructure it in a way that we solve the problem. We say: } \\
\text { "Oh! Now we have three cases from your department."' }\end{array}$ \\
\hline
\end{tabular}




\section{Occupational health services - the setting}

Public and private occupational health organizations work both internally and externally with their customers on health and safety issues in the workplace. Arbetsmiljöverket (the Swedish Work Environment Authority), which oversees such organizations, requires that independent experts in these organizations should be able to identify environmental work risks and find solutions to problems posed by these risks at the individual, group, and organizational levels (AML, Chapter $3, \mathbb{2 c}$ ). Thus, the occupational health organizations usually offer three services: employee rehabilitation, illness prevention measures, and health promotion consultation. They use multi-professional teams comprising physicians, nurses, physiotherapists/ergonomists, behavioral and other consultants, health educators, and engineers.

The organization we studied - OHCS - employs some 90 people and is located in Västra Götaland (VGR), a region in western Sweden that employs more than 50,000 people. OHCS mainly serves such VGR organizations as hospitals, dental clinics, and cultural institutions. OHCS customers enter into contracts for work-related individual rehabilitation, illness prevention, and health promotion services. Although OHCS has sold mainly rehabilitation services to its customers, in recent years, it has promoted its other two services because of the increasingly severe problem of sick-leave absences in the Swedish workplace. The national government, the employers' organizations, and the unions have complained for years that OHCS has repeatedly failed to deal with this problem (SOU, 2004: 113).

With this change in emphasis, OHCS appears to be trying to improve cooperation among its customers' managers and HR experts. The OHCS intend to teamwork, which can create productive and harmonious relationships. But current contracts between OHCS and its customers often lack clear objectives for cooperation with customers or clarity on the terms and techniques required to prevent illness or promote a healthy workplace. Moreover, contracts are signed annually, based on an estimated volume of various subservices for the coming year (particularly for rehabilitation services) and on case-by-case service use. To a considerable extent, current contracts are relatively inflexible.

\section{Results}

\section{Sources of weak signals}

We identified a number of sources of weak signals and learned how these signals were discovered and recorded. First-line managers typically discover weak signals initially because they are closely involved with the work and can observe the behavior and attitudes of the people they supervise. First-line managers often make these observations in the meetings they hold every morning, at which they see and hear the workers. Workers' questions and their tones of voice, facial expressions, and body language may indicate problems.

I try, therefore, to be in place when the night person leaves and am there for the first morning meeting when the small signals appear. There may have been a problem with a patient, and the physician has offered no support. (First-line manager) 
If workers have trust and confidence in their managers and their colleagues, they are likely to express their work concerns openly in these morning meetings.

First-line managers are responsible for observing the nurses at work. They have a special responsibility for recent nursing-school graduates, tracking how they manage their work. These managers must strike a balance between responsible supervision and authoritarian supervision, as they closely observe and listen to the workers. They hear the workers' discussions on their personal work situations and observe their behavior. In this way, the first-line managers discover weak signals of their workers' stress and dissatisfaction.

I need to understand if the newly hired nurses have an imbalance between work and other areas of their lives. Can they handle this situation or are they very near a breakdown, physically? I hear how they talk about their lives. (First-line manager)

In addition, we found other sources of weak signals. First-line managers review the workers' timecards to learn if they are working too many days or working too many long days. They notice if new nurses stay out very late, have irregular work schedules, and do not take work breaks. Furthermore, workers may talk directly to their first-line managers about their work. The managers consider these direct contacts especially useful when workers have concerns about colleagues who are experiencing work stress.

Managers may fail to detect weak signals early enough if they are concerned that workers may find an interest in their wellbeing more intrusive than sympathetic. If workers respond, 'Fine' when managers ask 'How are you today?' there seems no reason to pursue the matter. A manager's response of 'Really?' is likely to be interpreted as idle curiosity or even as a challenge. Workers who have taken short periods of sick leave, in particular, may feel mildly threatened by such follow-up questions. One manager reported that it encourages interactions to deal with problems before they become serious, and to encourage workers to speak to their managers if they are worried about colleagues. By institutionalizing these conversations, managers can raise these concerns sensitively with the workers' colleagues. Even if the colleagues react negatively, the managers have support, because they are following agreed-upon procedures for 'worry conversations'.

One difficulty with identifying the source of weak signals is determining which signals are 'right' signals and which signals merely constitute noise. In this regard, the physical proximity of managers to workers can be helpful. As work groups increase in size, however, it becomes more and more difficult for their managers to see and hear individuals.

With these early signals, one must separate serious noise from other noise. It is difficult. It depends somewhat on how large the work groups are that you manage and how distant you are from them. (First-line manager)

It is through professional closeness to workers as individuals that managers observe abnormal behavior rather than average group behavior. A worker's absentee patterns may be quite different from the normal attendance record, for example. This discrepancy may (or may not) mean that these absences should be classified as short-term sick leave. It is critical that each case be examined individually. 
After last summer we had several assistant nurses and registered nurses who took sudden short-term leave. Some were young girls who placed very high demands on themselves. Some did not have the required seven absence episodes that qualified them for rehabilitation. (First-line manager)

The primary weak signals that first-line managers discover are indications of problems evaluated from an individual perspective - signals that should be addressed before the situation becomes a case for rehabilitation. First-line managers with this worker perspective are well placed to detect such weak signals. Moreover, the meetings with OHCS specialists are useful for identifying how the new nurses perceive their work situation and if they have sought counseling. This information is communicated to first-line managers by the OHCS anonymously, so managers do not know the nurses' identities.

Another way to discover weak signals is through an examination of the workplace. OHCS has this ability because it is an investigative organization that is responsible for the safety of the workplace and the wellbeing of workers. It takes an organization-oriented perspective, and its members have acquired the experience to recognize unhealthy or unsafe workplace abnormalities.

We have discussed the situation when we have three or four cases from a department. As the association, we then analyse the situation and try to restructure it in a way that we solve the problem. We say: 'Oh! Now we have three cases from your department.' (OHCS specialist)

Newly employed nurses sometimes call OHCS to talk about their work stress and to make appointments to talk with a psychologist. An OHCS psychologist says that nurses from different hospitals often have similar problems. From these conversations with several nurses expressing the same concerns, the psychologist is able to gain a good understanding of the problematic work situations.

\section{Attending to weak signals as a process}

Our study reveals a number of ways that weak signals are attended to as a process. One of the best examples is the meeting format, which was formerly somewhat ad hoc, but has now been institutionalized. OHCS specialists, HR experts, and various hospital managers attend the breakfast meetings and soup lunches that occur four to six times per school term - almost monthly. The meeting agendas cover specific points, including the status review of current projects. In addition, small groups meet to discuss such issues and problems as how to work more proactively in groups. Participants report that they find these meetings productive because they have a clear agenda and structure.

First-line managers, HR experts, and OHCS specialists emphasize the importance of attending these group meetings. Since the introduction of group meetings, the cooperation and the relationships among actors are reported to have strengthened. In part, this has created the opportunity for the actors to compare their worker and workplace observations, allowing them to determine if action is required, as they work toward the same goal of preventing workplace illnesses while simultaneously conserving resources.

It seems to be essential in attending to weak signals that several people, perhaps in different places, have identified these signals and communicated about them with each 
other, allowing a pattern of weak signals to emerge. As more and more attention is paid to the weak signals, worrisome problems may become evident. Similar observations can then be placed in the same category, and necessary action is suddenly noticed. In this analytical stage, however, the participants take the individual-oriented perspective rather than the more organization-oriented perspective.

OHCS lacks channels to communicate its observations and analyses to senior hospital managers. When OHCS members see a pattern - several individuals from the same area requesting appointments, for example - it has no clear method for communicating that pattern to others. Because OHCS has no agreement with HR or hospital management for identifying patterns, there is no requirement for it to draft proposals for action plans.

There is no interest at the strategic level. What can we do when we have this perspective? Just remove us, and then see how we can develop the activities. Without this, it's just something that happens down here. I think that's the biggest flaw. (OHCS psychologist)

Thus, OHCS has little influence at the strategic level, because there is no detailed agreement between the parties on strategic cooperation.

\section{Sense-making from weak signals}

Positive examples demonstrate that it is possible to acquire insights about the need for preventive illness measures at the group level by making observations of single cases. There are also examples at the organizational level of group cooperation. The physicians and other health care professionals worked for 2 years to develop interdisciplinary teams, the goal of which was to simplify procedures and avoid unnecessary work, for the benefit of patients.

Our general impression is that the horizontal contacts among the first-line manager, the HR experts, and the OHCS specialists primarily developed in a natural and uncomplicated way. The organizational dimension is still not included in OHCS's mission, however. It still seems unlikely that OHCS will directly contact the first-line managers or the hospital directors concerning organizational development efforts, even though the first-line managers have worked to develop this proposal. OHCS's role at present is to make small efforts from time to time rather than trying to grasp the whole situation. Its members seem reluctant to work any differently, because of the possibility of cost increases.

The risk is that we may see something and think that we have to fix it, but it is too costly to fix. (OHCS psychologist)

The first-line managers also refer to pressure for an individually oriented perspective. They say a culture around organizational issues is lacking.

I also think there is a culture of seeing quite a lot at the individual level, or the group level. But it will be a long time before we achieve a system or organizational level. I rarely hear people talk about an organizational level. (First-line manager) 
Another problem related to the sense-making of weak signals is linked to the way people view their own competences and those of others. Given the first-line managers' competences and responsibilities, they tend to notice the general extent of workers' individual problems, often before these problems have reached the acute stage. OHCS specialists, who are assumed to have competence in the area of individual wellbeing, also focus on individual problems rather than organizational problems. First-line managers and OHCS specialists are united in their interest and competence in observing and dealing with the problems of individual workers.

The assumption is that first-line managers have adequate expertise to manage their hospital assignments - that trained medical personnel should also be able to solve organizational problems. The idea is that nurses or other health care professionals are capable of making such organizational changes as the physical and organizational design of new wards. Thus, pre-defined procedures with established patterns are used with internal organizational problems. There is little room for new ideas or new approaches. OHCS's other competences related to organizational issues, if they exist, are neither apparent nor applied.

It is so pre-programmed. We don't invite outsiders to contribute. We solve everything! We are experts, not only on illnesses but also on most everything else. (First-line manager)

Another obstacle to sense-making of weak signals is the structural scheme in the decision-making process. Decisions on organizational issues are made in a top-down process that makes it difficult for an outsider to participate at the right location, at the right time, and at the right level. If decisions are made at the top and trickle down, can an outsider be involved? When, or why, should an outsider try to become involved? Does someone have to be on the inside from the start in order to be helpful? Will the existing staff members monitor the outsider's participation? Should others ally with the outsider? Or simply ignore the outsider? These are complex questions that merit consideration.

Arrangements for the use of OHCS can also be a barrier to sense-making of weak signals. OHCS is similar in some respects to external management consultants. Only people at the highest level of a hospital - at the director level - have the resources to employ such external consultants, including OHCS. It is easier, and far less costly, to use internal resources in HR programs. Thus, it appears that the whole procedure of allocating funds to internal staff renders the use of external services extraordinary. This fact probably reinforces the hospital tradition of its own people solving all problems - a tradition that carries over to the use of OHCS services. Signing contracts or agreements with OHCS would become a critical issue, however, if it were possible for OHCS to work with a somewhat larger, organization-oriented mission.

\section{Prevention as a process - an analysis}

Here, we apply the four stages in a crisis process (Roux Dufort, 2009) described in the section entitled Weak signals and sense-making on situations at the hospitals we studied.

When we look at prevention as a process, the weak signals in Stage 1 should not be ignored. This is the stage when managers have direct contact with and close proximity 
to workers. Information collected in this stage can highlight behavioral or attitudinal anomalies (Weick, 1987). Roux-Dufort (2009) claims that Stage 2 is the most critical stage, however. It is in this stage that early preventive measures can prevent triggering events and ultimate destabilization, the stage at which 'wait and see' is a poor strategy (Pidgeon \& O’Leary, 2000; Reason, 1990).

The process of prevention requires acting on the 'right' weak signals, which, as we have observed, is no easy task. One approach to solving this problem is to rely on joint discussions among people with the experience and competence to evaluate weak signals in the workplace (Weick, 1987). In our study, first-line managers, the HR experts, and OHS nurses and psychologists form this professional network.

Day and Shoemaker (2004) suggest that a crucial situation arises if managers are unable to devote sufficient time to weak signals. But the hospital managers in our study are rarely too distracted from their main responsibilities that they cannot attend to weak signals. In fact, in our study, noting and interpreting weak signals are somewhat institutionalized as part of the hospitals' core illness-prevention process. According to Haeckel (2004), the hallmark of a successful organization is its recognition of the significant signals that precede a crisis.

The problem in Stage 2 for the preventive process appears to be the limited repertoire of actions of hospital managers, HR experts, and OHCS specialists (cf. Weick et al., 1999, 2005). The actors seem largely boxed in by the way the organizational structures and routines are designed and by the institutionalized procedures required for making change. In our study, the individually oriented perspective bears some responsibility for these policies. As Weick and Sutcliffe (2007) observe, there is a risk that individually oriented actions may lead to interpretations of weak signals that superficially suggest the existence of similarities between the earlier, well-known situations and the current situation. These restrictions in the use of allowable measures also apply to the competences of managers and their support staff.

Weak signals were interpreted in our study in relation to the individual and not to the individual's work conditions. Thus, in Stage 2, an imbalance arises between the individually oriented perspective and the organizationally oriented prevention - even in the successful examples the actors describe. The exceptions are the situations in which first-line managers have a strong and direct link to upper management. In such situations, first-line managers have access to people who may be assumed to have an organizationally oriented perspective and an action repertoire. An example is the work of the hospitals' physicians who are trying to develop well-functioning, interdisciplinary collaboration. Their hope is that this collaboration, which is one aspect of the illness-prevention process, can lead to improved working conditions for everyone, especially the nurses who have just completed their training and are new to the typical hospital workload.

Our study highlights the fact that OHCS is relatively well positioned to recognize weak signals linked to the organizationally oriented perspective, just as first-line managers are relatively well positioned to recognize weak signals linked to the individually oriented perspective. OHCS is limited in its action repertoire, however, because of its traditional way of working and its limited channels for communicating its findings to decision makers.

One obstacle to the implementation of illness-prevention measures in Stage 2 is the difficulty in establishing a link between the informal information, as revealed by the weak signals, and their interpretation, on the one hand; and formal information, as expressed in 
structured surveys and evaluations on the other hand. We found little evidence of this linkage in our research. Neither did we find a connection between either formal or informal information on workers' health and the formal data on production results. Hopwood's (2009) idea that informal information informs formal information does not appear to be a reality in our study; thus, the importance of the early weak signals has not been fully recognized and combined with formal data on matters such as sick leave and turnover.

As this study demonstrates, efforts to discover, interpret, and attend to weak signals are taken by first-line managers, who have direct contact with workers. Illness-prevention measures, when taken, are individually oriented. In successful situations, according to Roux-Dufort's (2009) model, progress to Stages 3 and 4 is often delayed or halted. However, in our study, we found that first-line managers charged with discovering, interpreting, and attending to the weak signals lack the necessary organizationally oriented perspective and the necessary action repertoire. For example, they lack access to channels that can transmit such informal information to upper management, where it could be combined with formal information in the decision-making processes. Ultimately, the illness-prevention measures produce inadequate outcomes, even in situations in which the weak signals are recognized as potential signs of serious problems. OHS seems to have done little to improve the situation.

\section{Discussion and Conclusions}

We interviewed managers, experts, and specialists who deal with occupational health illnesses among workers. Our approach was to look at the way in which weak signals of work stress and work dissatisfaction, if discovered at an early stage, can predict illnesses among workers. A key aspect of this activity is identification of the 'right' weak signals, because some weak signals may not lead to problematic or severe consequences. When the right weak signals are first discovered, managers and organizations should adopt, even institutionalize, illness-prevention measures at this early stage.

Overall, the study shows that horizontal communication among first-line managers, OHCS specialists, and HR experts related to detecting, processing, and sense-making of weak signals functioned relatively well. This probably means that the OHCS specialist attends to and makes sense of different types of weak signals than leaders and HR experts do. Our study describes several examples in which first-line managers at several hospitals used managerial measures intended as responses to anomalies in workers' behavior and attitudes (i.e., the weak signals). First-line managers, OHCS specialists, and HR experts are able to discover, interpret, and attend to significant weak signals related to workers' health when there is mutual trust among the actors and confidence in each other's legitimacy.

Creating and maintaining trust and confidence requires a high level of communication competence. The actors must engage in transparent dialogues, discuss similar concerns and issues, and listen and watch for weak signals. These results are consistent with the assumption that the mutual trust created in horizontal communications among actors support the practice of safety in the workplace (Törner \& Pousette, 2009). With respect to our research, the value of the service provided by OHCS specialists depends on their position in the network of first-line managers and HR experts. Weak signals first emerge in this network where workers' health problems are observed and discussed.

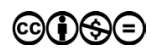


The beneficial effects of the relatively well-functioning horizontal communication were limited to individually oriented measures (e.g., mentoring and counseling) in contrast to organizationally oriented measures. Among these individually oriented measures, we identified mentoring, counseling, and talk therapy, the goals of which are to promote a healthy work-life balance. Yet, these effects are also limited because of problems in the vertical communications. First-line managers, who are well positioned to discover (and do discover) weak signals, think they lack effective communication channels for sending workers' concerns and issues to upper-level management, where more organizationally oriented illness-prevention measures may be taken.

The first-line managers report some frustration because the informal (local) information seems to have minimal influence on the interpretation of such formal information as surveys. They also believe that they cannot overcome this problem or counterbalance its negative outcome because of a lack of an organizationally oriented repertoire of measures they could use. This is true even for the OHCS specialists, despite their better opportunities to discover organizational patterns in work-related illnesses.

In this article, we emphasize the importance of identifying the right weak signals and making sense of them using a complex mixture of formal and informal information - the responsibility of first-line and upper-level managers. Although sense-making from informal information based on weak signals may lead to early, preventive action, this action is limited to individually oriented measures. On the contrary, sense-making from formal information may lead to organizationally oriented measures, but preventive action may be delayed to the detriment of individual wellbeing. This conclusion is consistent with Preston's (1986) study describing the ease with which managers can achieve their mission if they are able to combine formal information (e.g., statistics and surveys) with informal information (e.g., rumors and gossip) at organizational decision-making levels. Thus, informal information increases people's ability to understand formal information and thereby their ability to act in cooperation with other actors.

We offer a suggestion on how the communication of formal information can influence upper-level managers as they deal with formal information. It may be difficult to mobilize upper-level managers into action through descriptions of weak signals not yet interpreted as relevant. The almost-inevitable tendency when people encounter vague concerns and issues not yet fully apparent is to take a wait-and-see approach. The concerns and issues reflected by weak signals should therefore be communicated as sense-making stories with specific, relevant details. First-line managers must have confidence in the HR experts and the OHCS specialists if they are (jointly) to construct and communicate these stories.

In summary, we emphasize our principal conclusion about the necessity for detailed information in safety communications. All actors should be receptive to weak signals, whatever their source. Such responses require close proximity to the individuals who transmit these weak signals. Informal information can provide a useful supplement to formal information, particularly when the two information streams are interpreted together. Both individually oriented and organizationally oriented illnessprevention measures have value. Moreover, stories created and told by actors working together are likely to include more information than are stories created by individuals working alone. Storytelling success is possible only through the existence of effective actor communication channels. In some respects, the organization may be better equipped to develop, implement, and oversee a more comprehensive and effective 
healthy workplace environment with effective communication systems than can any number of managers, working separately.

Previous studies (Andriessen, 1978; Hofmann \& Stetzer, 1998; Törner \& Pousette, 2009 ) investigating the effect of various variables on health and safety performance have concluded by primarily emphasizing the importance of communication between managers and workers. The contribution of our study to OHS research is to describe, using a theoretical framework not previously used in health and safety management studies: the content of the communication among first-line managers, workers, personnel experts, and occupational health care specialists, as they deal with informal information as weak signals in health care and safety work. Furthermore, our study suggests that organizational solutions continue to produce or worsen workers' health problems, despite the possible negative effect at the field level, where early and weak signals indicate that the organizational solution is unhealthy. It is difficult to improve traditional health and safety work based on the formal information from formalized procedures that upper management relies upon because of difficulties in adopting the use of informal information to supplement the formal information.

\section{Practical implications}

At OHCS, in its present form, upper management seems to lack the necessary means to address organizationally oriented, illness-prevention measures at an early stage, when such action is expected and needed. It is not enough that OHCS specialists aim for improved horizontal collaboration and better 'customer dialogues' with HR experts and first-line managers. Improvements in cooperation and vertical communication with upper-level management are also needed. It is likely that such improvements depend on changes in the actors' communication channels.

Anomalous stories about weak signals may not be communicated adequately through formal information channels. Informal information channels, which can originate with workers or managers, may be more effective. This article presents empirical examples of how several organizations found it productive to have certain meetings (e.g., breakfast meetings and soup lunches) and that these meetings were efficient ways for its members to discuss preventive work. Such discussions may allow HR experts and OHCS specialists to adapt their formal information channels in ways that make the workers' everyday concerns more descriptive and more relevant, rendering the professionals' information about weak signals more useful to upper-level managers. Thus, all actors can form a partnership that is more likely to formulate and achieve strategic aims for work-related illness prevention. In this process, the sustainable organization should develop a common language for use by managers, specialists, and experts.

Although it may be a cliché, it is nevertheless true that information overload is a constant threat to effective communication. Sense-making stories, such as we advocate, may contain a great deal of information that may, regrettably, be ignored. This is a dangerous response, because these stories can convey a great deal about an organization's challenges and how they can best be managed. Stories based on early weak signals aid in the understanding of uncertainty and help organizational leaders to deal with it, as they plan for the unexpected. Stories, based on early, weak signals, describe what has happened, what is happening now, what will happen next, and why. 


\section{Future research}

Our study indicates that more participatory research methods are needed to study the managing of weak signals, as an aid to understanding the methods actors use to get at the root causes of weak signals - methods that go beyond intuition. Furthermore, this study addresses the challenge of achieving lasting results with illness-prevention measures, leading to our conclusion that it is difficult to influence upper-level managers with informal information produced locally. Further research is needed to investigate the influence of informal information on the interpretation of formal information. We need to know more about the design of informal information, how it can produce a coherent, convincing narrative, and how such information can best be transmitted. In addition, there is need for more research to examine mutual trust among actors and the way it supports trust in informal information. This is a call for research that continues to examine the strategic partnerships among HR experts, OHCS specialists, and managers at all levels of the organization.

\section{References}

Ahnmé Ekenryd, C., Nylund, K., Jensen, I., \& Eklund, J. (2012). Forskning och utveckling inom företagshälsovården - behov och förutsättningar [Research and development in occupational health - needs and conditions]. Stockholm: Karolinska Institutet.

Alvesson, M. (2003). Beyond neopositivists, romantics and localists: A reflexive approach to interviews in organizational research. Academy of Management Review, 28, 13-33. doi: http://dx.doi.org/10.5465/AMR.2003.8925191.

Andriessen, J. H. T. H. (1978). Safe behaviour and safety motivation. Journal of Occupational Accidents, 1(4), 363-376. doi: http://dx.doi.org/10.1016/0376-6349(78)90006-8.

Ansoff, H. I. (1975). Managing strategic surprise by response to weak signals. California Management Review, 18(2), 21-33. doi: http://dx.doi.org/10.2307/41164635.

Arbetsmiljöverket (2016). Lag och rätt: Arbetsmiljölagen. [Law and rights: Workplace Law].

Charmaz, K. (2006). Constructing Grounded Theory: A Practical Guide through Qualitative Analysis. Thousand Oaks, CA: SAGE.

Cunha, M., \& Chia, R. (2007). Using teams to avoid peripheral blindness. Long Range Planning, 40, 559-573. doi: http://dx.doi.org/10.1016/j.lrp.2007.08.004.

Day, G., \& Schoemaker, P. (2004). Peripheral vision: Sensing and acting on weak signals. Long Range Planning, 37, 117-121. doi: http://dx.doi.org/10.1016/j.lrp.2004.01.003.

Denzin, N. K., \& Lincoln, Y. S. (Eds.) (2011). The SAGE Handbook of Qualitative Research. Thousand Oaks, CA: SAGE.

Gallagher, C. (2000). New directions: Innovative Management Plus Safe Place. Occupational Health \& Safety Management Systems: Proceedings of the First National Conference. University of Western Sydney, Australia, July 2000.

Haeckel, S. H. (2004). Peripheral vision: Sensing and acting on weak signals making meaning out of apparent noise: The need for a new managerial framework. Long Range Planning, 37, 181-189. doi: http://dx.doi.org/10.1016/j.lrp.2004.01.006.

Hall, M. (2010). Accounting information and managerial work. Accounting, Organizations and Society, 35, 301-315. doi: http://dx.doi.org/10.1016/j.aos.2009.09.003.

Hedberg, B., \& Jönsson, S. (1978). Designing semi-confusing information systems for organizations in changing environments. Accounting, Organizations and Society, 3, 47-64. doi: http://dx.doi.org/10.1016/0361-3682(78)90006-5. 
Hofmann, D. A., \& Stetzer, A. (1998). The role of safety climate and communication in accident interpretation: Implications for learning from negative events. Academy of Management Journal, 41(6), 644-657. doi: http://dx.doi.org/10.2307/256962.

Hohnen, P., \& Hasle, P. (2011). Making work environment auditable-A 'critical case 'study of certified occupational health and safety management systems in Denmark. Safety Science, 49(7), 1022-1029. doi: http://dx.doi.org/10.1016/j.ssci.2010.12.005.

Holopainen, M., \& Toivonen, M. (2011). Weak signals: Ansoff today. Futures, 44, 198-205. doi: http://dx.doi.org/10.1016/j.futures.2011.10.002.

Hopwood, A. (2009). The economic crisis and accounting: Implications for the research community. Accounting, Organizations and Society, 34(6-7), 797-802. doi: http://dx.doi. org/10.1016/j.aos.2009.07.004.

Hsieh, H. F., \& Shannon, S. E. (2005). Three approaches to qualitative content analysis. Qualitative Health Research, 15(9), 1277-1288. doi: http://dx.doi.org/10.1177/1049732305276687.

Jönsson, S. (1998). Relate management accounting research to managerial work! Accounting, Organizations and Society, 23(4), 411-434. doi: http://dx.doi.org/10.1016/S03613682(97)00018-4.

Kamp, A., \& Le Blansch, K. (2000). Integrating management of OHS and the environmentParticipation, prevention and control. In K. Frick, P. L. Jensen, M. Quinland, \& T. Wilthagen (Eds.), Systematic Occupational Health and Safety Management: Perspectives on an International Development (pp. 413-436), Oxford: Pergamon.

Kvale, S. (1996). InterViews. An Introduction to Qualitative Research Interviewing. London: SAGE

Patton, Q.M (2001). Qualitative Research \& Evaluative Methods. London: SAGE.

Pidgeon, N. (1998). Safety culture: key theoretical issues. Work \& Stress, 12(3), 202-216. doi: http://dx.doi.org/10.1080/02678379808256862.

Pidgeon, N., \& O’Leary, M. (2000). Man-made disasters: Why technology and

organizations (sometimes) fail. Safety Science, 34(1-3), 15-30. doi: http://dx.doi.org/10.1016/ S0925-7535(00)00004-7.

Preston, A. (1986). Interactions and arrangements in the process of informing. Accounting, Organizations and Society, 11(6), 521-540. doi: http://dx.doi.org/10.1016/03613682(86)90034-6.

Reason, J. (1990). Human Error. Cambridge, UK: Cambridge University Press. doi: http:// dx.doi.org/10.1017/CBO9781139062367.

Rootman, I. (Ed.). (2001). Evaluation in Health Promotion: Principles and Perspectives (No. 92). WHO Regional Office Europe.

Rossel, P. (2011). Beyond the obvious: Examining ways of consolidating early detection schemes. Technological Forecasting \& Social Change, 78, 375-385. doi: http://dx.doi. org/10.1016/j.techfore.2010.06.016.

Rocha, R. S. (2010). Institutional effects on occupational health and safety management systems. Human Factors and Ergonomics in Manufacturing \& Service Industries, 20(3), 211-225. doi: http://dx.doi.org/10.1002/hfm.20176.

Roux-Dufort, C. (2009). The devil lies in details: How crisis builds up within organizations. Journal of Contingencies \& Crisis Management, 17(1), 4-11. doi: http://dx.doi. org/10.1111/j.1468-5973.2009.00563.x.

SOU 2004: 113, Utveckling av god företagshälsovård - ny lagstiftning och andra åtgärder. Betänkande av 2003 års företagshälsovårdsutredning [Development of good workplace healthcare-new legislation and other measures: Results from the 2003 workplace healthcare investigation]. Stockholm: Fritzes.

SOU 2011: 63 Framgångsrik företagshälsovård - möjligheter och metoder. [Successful workplace health care-possibilities and methods]. Stockholm: Fritzes. 
Strauss, A., \& Corbin, J. (1990). Basics of Qualitative Research (Vol. 15). Newbury Park, CA: SAGE.

Turner, B. (1978). Man-Made Disasters. London: Wykeham Publications. doi: http://dx.doi. org/10.1177/017084068000100313.

Turner, B. A. (1976). The organizational and interorganizational development of disasters. Administrative Science Quarterly, 21, 378-397. doi: http://dx.doi.org/10.2307/2391850.

Törner, M., \& Pousette, A. (2009). Safety in construction-a comprehensive description of the characteristics of high safety standards in construction work, from the combined perspective of supervisors and experienced workers. Journal of Safety Research, 40(6), 399-409. doi: http://dx.doi.org/10.1016/j.jsr.2009.09.005.

Weick, K. E. (1987). Organizational culture as a source of high reliability. California Management Review, 29, 2, 112-127. doi: http://dx.doi.org/10.2307/41165243.

Weick, K. E. (1988). Enacted sensemaking in crisis situations [1]. Journal of Management Studies, 25(4), 305-317. doi: http://dx.doi.org/10.1111/j.1467-6486.1988.tb00039.x.

Weick, K. E., \& Sutcliffe, K. M. (2006). Mindfulness and the quality of organizational attention. Organization Science, 17(4), 514-524. doi: http://dx.doi.org/10.1287/orsc.1060.0196.

Weick, K. E., \& Sutcliffe, K. M. (2007). Managing the Unexpected: Resilient Performance in an Age of Uncertainty, 2nd Ed. San Francisco, CA: Jossey-Bass.

Weick, K. E., Sutcliffe, K. M., \& Obstfeld, D. (1999). Organizing for high reliability: Processes of collective mindfulness. In B. M. Staw, \& L. L. Cummings (Eds.), Research in Organizational Behavior, (pp. 81-123). Greenwich, CT: JAI Press, Inc.

Weick, K. E., Sutcliffe, K. M., \& Obstfeld, D. (2005). Organizing and the process of sensemaking. Organization Science, 16(4), 409-421. doi: http://dx.doi.org/10.1287/orsc.1050.0133.

\section{Notes}

${ }^{1}$ In Sweden, OHCS is organized either in independent organizations operating in a market of customer organizations or, as in the case described here, as a separate unit within a larger organization.

${ }^{2}$ SOU 2004: 113 describes prevention as 'a preventive action taken to prevent disease or illness' in three stages. The first stage deals with primary prevention, with a focus on eradicating the factors that can cause disease or illness. Secondary prevention is aimed at an early stage, in order to identify and correct health risks. Tertiary prevention refers to the attempt to reduce the health risks and any consequences that may exist. 